\title{
Endpoint Dilution Assay
}

National Cancer Institute

\section{Source}

National Cancer Institute. Endpoint Dilution Assay. NCI Thesaurus. Code C120684.

An in vitro cell based assay in which plated host cells are inoculated with serial dilutions of an infective agent and observed for cytotoxic effects in order to calculate the titer. 